\title{
14. Skyfall and Global Casino Culture
}

\author{
Joyce Goggin
}

\begin{abstract}
This chapter analyzes the signifying potential of gambling and casino culture as a seminal feature of James Bond-ness and the 007-universe. It argues that gambling and casinos, both of which are updated with every new outing of James Bond, have important cultural, political and economic ramifications. In particular, the chapter asks how and what casino gambling signifies as it is updated in Skyfall (2012), in terms of the film's mise-en-scène as well as its geopolitical configuration as a colonizing industry in a global economy that is increasingly dependent on various forms of gambling. Finally, the chapter connects various aspects of what has been referred to as "cinematic revisionism" to the politics and economics of neoliberalization, 007 , and global casino culture.
\end{abstract}

Keywords: Skyfall, gambling, casinos, globalization, finance, Macau

The notion that a particular logic and dynamic reside at the heart of the 007 franchise, lending it durability as a function of its capacity to project hipness, newness and traditional "Britishness" all at the same time, has become something of a truism in popular and scholarly writing on Bond. For example, in The Man Who Saved Britain, commercial author Simon Winder has outlined the many ways in which Bond has been rebooted to serve the economic and political aims of various parties involved in the production of the series over time. Similarly, Charlie Higson $(2012,37)$, on the fiftieth anniversary of the release of Dr. No (UK: Terence Young, 1962) and the twenty-third outing of Bond in Skyfall (UK/USA: Sam Mendes, 2012), writes that "[e]ach new incarnation of Bond (very loosely) fits a decade and speaks to each new generation" so that it is "fascinating to chart how each Bond cleverly manages to personify an era and even define it."

Verheul, J. (ed.), The Cultural Life ofJames Bond: Specters of oo7. Amsterdam: Amsterdam University Press, 2020 DOI 10.5117/9789462982185_CH14 
In scholarly work on 007, much has been made of the British spy's ability to trend-set, and to inform the periods in which the films were produced, hence Tony Bennett and Janet Woollacott's $(1987,13)$ argument that James Bond functions as a mobile "sign of the times," who is "capable of taking up and articulating quite different and even contradictory cultural and ideological values," often rearticulating these values in such a way as to enunciate new, or at least revamped versions thereof, that also resonate with tradition. Likewise, James Chapman $(2005,129)$ offers a detailed compendium of numerous "moments of Bond," following how each installment is updated stylistically and ideologically so as to appeal to viewers over time, from the Cold War, through the era of "swinging Britain", to the threat of cyberterrorism. In a related vein, Craig N. Owens $(2005,107-8,110)$ explains how the franchise and the character manage to sustain the "nasty habit of surviving" by serving as a "kind of ontological blank" whose name-007-suggests "a blank at the center of his identity" so that his "mixable, dilutible essencelessness seems to confirm the sense that he [...] is a real cipher." And Michael Denning $(2009,58)$ has argued that "each set of attributes" and characteristics that we might ascribe to this essence-less cipher comprise a "figure who has been accented in a number of ways," so that Bond is - and is not - the collection of accoutrements by which we know him, such as the Aston Martin, martinis, sophisticated gadgetry, exotic destinations and so on.

In what follows, I subscribe to the notion that the 007-concept serves as a base that may be updated and reconfigured handily and often in order to keep up with differing tastes and viewer demands. In doing so, I will focus my argument on casino culture, which holds a prominent place in the Bond universe, while simultaneously revealing how gaming and the greater economy work in tandem as represented in the myriad of James Bond casino scenes, beginning with the very first one in Ian Fleming's Casino Royale (1953). My specific aim is to unpack the casino scene in Skyfall and, to a much lesser extent, the casino scene in Man with a Golden Gun (UK: Guy Hamilton, 1974) in order to discuss what these scenes and their settings tell us about various styles of economic management, regulation or the lack thereof, and the underlying political systems which enabled them when the films were made.

\section{Backing Up to Move Forward}

Given the body of popular and academic work that focuses on the adaptability and perpetual novelty of Bond within the purview of tradition, I want 
to discuss $S k y f a l l$, a film that likewise situates itself in relation to tradition as a means of innovating, seemingly in reverse of many of the previous Bond films. In this regard it is notable that $S k y f a l l$ belongs to a prequel quartet that includes Casino Royale (UK/Czech Republic/USA/Germany/Bahamas: Martin Campbell, 2006), Quantum of Solace (UK/USA: Mark Forster, 2008), and Spectre (UK/USA/Austria/Mexico/Italy/Morocco: Sam Mendes, 2015), which quartet is marked by a number of features also common to other film franchises to which the term "revisionist" is frequently applied. Various authors have used the term "revisionist" to describe some of the more salient features of this predominantly American trend in cinema that began in the late 1990s, including a "gritty noirish" aesthetic and feel (Lindner 2009, 2); a "more realistic look" and a "certain 'retro' style" (Chapman 1999, 249), a "total disavowal of previous titles and events in the series" (Lindner 2009, 2); a repositioning of Bond "at the start of his career as if the events in previous films had not taken place" which often goes hand in hand with a reinvigoration of the series accomplished by going back to basics or "bare essentials" (Chapman 1999, 249); and Bond's new-found capacity to age which includes "fallibility and vulnerability" (Lindner 2009, 2).

In the Bond prequels, revisionism offers us insights into Bond's life as "the orphan child recalled in Casino Royale" and affords us an opportunity to sympathize with "the death of his lover that hardens [007's] sense of purpose as exhibited in Quantum of Solace" (Dodds 2014, 118). We also become acquainted with a damaged yet rehabilitated Bond in Skyfall, along with "a substitute father figure;" in this case the gamekeeper of the Scottish Bond mansion in Skyfall (Dodds 2014, 118). This dual temporal movement belongs to what Monika Gehlawat $(2010,131)$ has characterized as a "dialectic of old and new [...] crystalized in the latest Bond film[s] where Daniel Craig presumably represents 007 in his originary form and, in so doing, shows him at his most contemporary."

While revisionism fills in the backstory, it also adds a layer of grit and historical authenticity — at least where the Bond franchise is concerned — to a series that was threatening to lose its capacity to impress viewers with special effects. At the same time, revisionism is political as well as aesthetic because it rewrites the past through the addition of explanatory plot twists or visual and aesthetic clues which support a particular stamp of, in this case, conservative or retrogressive leaning. One such detail in Skyfall is M's old-fashioned china bulldog that Bond inherits at the close of the film, painted to look like the Union Jack and therefore, to signal Empire. As I will argue, however, there is more at stake in metonymically connecting an aging James Bond to signifiers of Britain's past such as J. M. W. Turner's 
portrait of a gunship being towed away to a scrapyard, captured in his The Fighting Temeraire (1839), which also makes an appearance in Skyfall. As Q meets Bond by the painting in the National Gallery, he quips that it always makes him "feel a little melancholy [to see] a grand old warship being ignominiously hauled away to scrap." The deeper significance of such details has been noticed by critics commenting on the politics of this film, who tend to concur that it is impossible to view Skyfall independently of markers of Empire and earlier times, and to not "think back to a time when one-quarter of the globe was painted imperial red"-in other words, it is well-neigh impossible to overlook the film's political implications and innuendos (Hasian 2014, 580).

In what follows, I will read the film's aesthetics, and its many nostalgic references to some purportedly more "authentic" past when the nation was "great," as political gestures aligned with, and on occasion perhaps critical of, what is known as neoliberalism. The term "neoliberal" was coined to describe the behavior and policies of "free marketers," and is often used as a blanket term to describe "free trade' or simply 'globalization"” while it invariably involves "the elimination of the public sphere, total liberation for corporations and skeletal social spending” (Klein 2007, 14-15). Neoliberalism also entails a shift away from "government action in the form of fiscal policies (taxation) and federal expenditures, to monetary policies [whose] faith in the market [leads] to suspicions about too much government intervention," while "promoting policies to deregulate and privatize banking, financial services, information and network technology and telecommunications" (Taylor 2004, 6-7). Neoliberalism is also distinguished by the imposition of "flexible labor markets so as to get longer working hours and more intensive production" from workers, combined with "cut[ing] back on welfare expenditure" in favor of "marketization and privatization" (Harman 2009, 240). Given the above, neoliberal policies have consistently supported the destruction of much of what until recently still belonged to the present (the publicly funded maintenance of infrastructure, the social safety net, liberal politics, the freedom of certain kinds of speech), ostensibly as a means of returning to, or convincing citizens that it is possible to return to, an idealized, largely fictional, past era of greatness.

Skyfall's relationship to neoliberalism is apparent in numerous aspects of the film, such as its "distressed or decaying aesthetic," mirroring the results of neoliberal economic policies that erode government expenditure in the public sphere, or the film's depiction of the reigning, purportedly global, "world view" (Gehlawat 2010, 133). In describing what that world view might look like when depicted in a Bond film, Gehlawat $(2010,131)$ explains_-in 
the context of Casino Royale - that this world view is evidenced in an "unexpected but logical turn" to "the destructive character [that] stands in the front line of traditionalists." "Simply put," writes Gehlawat (2010, 134), Bond's "destructive character, in clearing away all that came before, represents the advent of a new tradition," wiping the slate clean in order to establish a new order and to erect new institutions that paradoxically claim a special, direct relationship to tradition and to the past.

Therefore, various aspects of $S k y f a l l$, such as the presentation of a fallible 007 who abandons high-tech weaponry at the close of the film in favor of good, old-fashioned booby-trapping of the Scottish manor where he grew up, may be at least tangentially linked to the politics of neoliberalism. While such vintage details, together with Bond's own avowal that he is an "old dog" who can't be taught "new tricks" may be charming and quaint, the devil is in the details. My goal is to connect the franchise's characteristic projection of newness and tradition, in combination with the tenets of revisionist cinema and various characteristics commonly associated with the economics and politics of neoliberalism, to the representation of gambling and casino culture in Skyfall — as indeed economics and politics have resonated through the Bond franchise as a whole.

\section{"Bond Has Always Been a Gambler"}

In one of his more poetic moments, Fleming (1953) wrote that 007 had never "been made to suffer by cards or by women," and that Bond equates luck with "women, to be softly wooed or brutally ravaged." Just as the Bond Girl has been a standard feature of the franchise since its beginnings, so too the spy's steely-eyed proficiency as a gambler has become a standard signifier of Bond-ness. Therefore, as Klaus Dodds $(2014,123)$ has noted, 007's "impeccable appearance in a dinner jacket" as he arrives on the casino floor in various instalments of the franchise are part and parcel of the "long-standing trademark of his gambling prowess" and masculinity. Hence, as the Vegas Master website (Vegasmaster) would have it, "[a]lthough you won't find Bond at a casino in every movie, casinos are commonly associated with the fictional secret agent, about as much as 'shaken, not stirred' dry martinis." From the first novel, named after a casino, to scenes set in Las Vegas in Diamonds are Forever (UK: Guy Hamilton, 1971), to the Macau casino featured in The Man with the Golden Gun (UK: Guy Hamilton, 1974), and the CGI Macau casino created for Skyfall, gambling, as a sign or mobile signifier, blends seamlessly into the ambient texture of fast cars, easy women, 
and shaken martinis. The question that remains to be answered, however, is how casinos and gambling signify at various moments in the history of Bond, and why this is politically and economically significant.

As I have argued elsewhere (Goggin and Glass 2010), one good example of how gambling signifies in the Bond universe may be read in the shift from Baccarat in Fleming's Casino Royale (1953) to Texas Hold'em in the 2006 film adaptation. The shift is indicative of various cultural and economic developments that were underway in 2006 , such as the global popularity of Texas Hold'em at the time of the film's release. Therefore, changing the game from Baccarat to Texas Hold'em in the film effectively adds a modern detail to the story for contemporary viewers who would have been familiar with Texas Hold'em from televised tournaments, the internet and countless other sources, whereas they might not have been familiar with the older game of Baccarat. One might also conjecture that the switch was intended as a subtle reference to the Texan-George W. Bush-who was occupying the White House in 2006 (Goggin and Glass 2010). In other words, Texas Hold'em was substituted in order to update the novel written in 1953 for audiences viewing its cinematic adaptation in 2006 - a game much more familiar to audiences than Baccarat.

To delve deeper into the seemingly minor gesture of changing a card game from novel to film adaptation and what it might mean, I want to unpack some of the signifiers of gambling culture in which the Bond franchise abounds, along with what these signifiers may communicate to viewers. Take, for example, a somewhat less obvious historical dimension of Poker of which viewers may not be consciously aware, but which comes to light if one considers the significance of updating Baccarat in Casino Royale by replacing it with Texas Hold'em in the 2006 film adaptation. One of the reasons that Poker is so often represented in film and television is connected to the game's popularity and tenaciousness across recent history, due in part to poker's peculiar adaptability. Poker owes its malleability to its origins as a nineteenth-century American hybrid of older European card games including Primero, Brag, Bouillotte, Poch, and Poque that entered the United States with various waves of immigrants (Parlett 1992, 208). Since its invention in the United States two centuries ago, Poker has morphed into numerous variants that reflect the historical juncture and the economic context in the nineteenth or twentieth century in which the variants developed, such as industrial capitalism or our current, largely finance-driven economic order. Hence, as Ole Bjerg (2011, 5, 222-3) has argued, "the evolution and succession of different forms of poker, Flat poker, Draw poker, Stud poker, and Texas Hold'Em, corresponds to the evolution and succession of different 
paradigms of capitalism," with the recent Texas variant closely resembling "postindustrial capitalism, where financial markets tend to constitute a reality of their own decoupled from the sphere of the productive economy" so that the game is now so closely aligned with the economy that playing it has become an "unimaginative", "mechanical" and "disciplined job." Likewise, the "no limit" feature of Texas Hold'Em is misleading because the continuance of both the game and the market must logically and finally depend on the availability of funds which, even though one can borrow, eventually run out.

More recently, Ed LiPuma (2017) has adopted Bjerg's argument to argue for the existence what he has called "poker nation," which describes life in the global speculative economy based on market models that got their start in Western Europe in the eighteenth century and were further developed in the United States. According to LiPuma (2017, 256), because the global economy is now reliant on the financial markets and therefore on speculation which has only been divorced from gambling by the introduction of various laws such as the Gambling Act of 1774 in England, "speculation has gone public and global." Citizens of the said poker nation constitute "a community whose self-defining act and determination is the risk driven wager" (257), whether the wager in question is taken voluntarily and at leisure on the green felt, or involuntarily in the form of one's pension which is now invested in the market whether one cares to speculate or not. The poker nation is ultimately a social imaginary that entails a "shared understanding and habitus" in which "gambling and speculation have come out of the back room and assumed [...] a visible and marketable place in the public sphere" (257), be it in the form of gambling narratives, 007 movies, gambling vacations taken in places like Las Vegas, or in popular events like poker tournaments.

The Bond novels and films that contain gambling scenes extend the card-playing logic - the level of risk involved, maximum bets as opposed to no limit, the amount of information concealed, revealed, or bluffed-from specific card games such as Baccarat, Poker, and Gin Rummy, and from how they signify in the worlds of Bond, to the larger scene of the casino. The card-playing logic to which I refer also informs economic and cultural developments such as the tremendous expansion of the gambling industries over the last several decades as a key driver in the global economy, in which the industries themselves also rely on a form of entertainment involving on risk taking and speculation. Indeed, the current post-industrial capitalist paradigm has given rise to an economy that relies heavily on all of those things that make Bond special: risk taking, speculation, entertainment, excitement, sensation, and travel. 
Hence, as in my previous example from Casino Royale, updating and Americanizing the novel's older European game of Baccarat by replacing it with Texas Hold'em in the film is symptomatic of a significant shift in gambling cultures that we see reflected in casino décors and the games on offer, as well as in the economic paradigms in which the films and novels are set. This shift is likewise visible in the ways in which casinos are depicted in other Bond films, from Las Vegas - a place that Fleming both ridiculed and venerated -in Diamonds are Forever (1956) and Thrilling Cities (1957), to the nineteenth-century style Casino Royale in Montenegro in Casino Royale, the Casino de Macau in The Man with the Golden Gun, and the stupendous CGI "Macau casino" in Skyfall with its retro-oriental theme.

\section{Casino Cultures}

As I have been arguing, 007 is a gambler and many if not most of the novels and films contain a significant gambling scene, while at the same time, the global economy has become increasingly financialized — that is, dependent on investment banking and the financial markets. In order to understand the full significance of Macau and its CGI representation in Skyfall in light of these observations, I will now turn to a discussion of the history of casino cultures as represented in the worlds of Bond.

Importantly, Fleming himself paid particular and prescient attention to the gambling industries which would come to form such an important part of the global economy, evidenced in everything from the spread of Las Vegas themed franchises, casinos on First Nations reservations, and televised poker tournaments, which in turn are all part of how the global speculative economy generates wealth. Fleming's prescience is particularly evident in Diamonds Are Forever, which contains a segment set in Las Vegas, a city which itself was updated over a period of time spanning the publication of Fleming's novel in 1956 to the film adaptation released in 1971. The relationship between 007 the gambler, the gambling scenes depicted in Fleming's narratives, and the role of gambling as an industry becomes clear in the novel as Bond enters the city via the emerging Strip, described by Fleming (1956) as a road that "was beginning to sprout gas stations and motels" in the desert, empty "except for occasional hoardings advertising the hotels." Along this textual trajectory, Bond's cab driver points to new casinos that were springing up - the Flamingo, the Sands, the Desert Inn, the Sahara, the Last Frontier and the Thunderbird — all of which would have seemed slightly dated by the time the film adaptation was released in 1971, when 
Fleming's description of the Strip as still being largely undeveloped would no longer have been accurate (Goggin 2010; 2015).

In the film adaptation of Diamonds Are Forever, as in the example of the card game in Casino Royale, the way in which this scene and the casino setting are updated represents more than an architectural face-lift or a switch to a trendier Vegas theme (Goggin 2011). While Fleming presents a bleak view of the desert capital and the largely deserted yet developing Strip, he also foresaw fiscal policies that loomed large, such as the Gambling Act of 1967 , and which began to take hold in the 1970s at about the same time that Sean Connery arrived in Vegas to begin filming Diamonds are Forever. By 1971, for example, the city had made considerable advances toward going straight and courting wider middle-class recognition, some of which is attributable to Howard Hughes, who took up residence in Las Vegas in 1967, and bought the Desert Inn, followed by the Sands, the Landmark, Castaways, the Silver Slipper, and the Frontier, thereby contributing significantly to the further development of the Strip (Rothman 2003, 20). More importantly, Hughes used his political influence to help push through the Corporate Gaming Act in 1967 , making the gambling industry a legitimate public offering that could attract corporate investment and the kind of large scale financing not previously available through "mob" channels (Schwartz 2003, 133).

Ultimately the Gaming Act would lead to the repackaging of gambling as "gaming:" a government-endorsed, normalized and, to a certain extent, sanitized product, as reflected in Fleming's (1956) novel Diamonds Are Forever, in which Felix Leiter's asserts that the hoodlums are increasingly in charge and beginning to "run governments. State governments like Nevada." Therefore, while Fleming was writing the novel, Las Vegas was learning to frame gambling as an acceptable, government-approved, middle-class leisure activity, presented in a more diversified package that included family activities. While in the novel, catering to middle America is lamented (for example, Fleming has Bond sarcastically take note of a pool sign that reads, "LIFESAVER: BOBBY BILBO-POOL SCOURED DAILY BY HYDRO JET"), Hollywood backers worked together with Vegas developers on the 1971 film adaptation of Fleming's novel to showcase Circus Circus, the first casino-hotel on the Strip to feature a family theme. Shot precisely to highlight every aspect of this casino on offer to family guests when it opened, the film is more like an adaptation of Circus Circus' own advertisements in the 1970s, which announced the "[W]ORLD'S LARGEST GAMING AND ENTERTAINMENT CENTER," with "GIRLS! GIRLS! GIRLS! ELAPHANTS, 14 BARS AND RESTAURANTS, SHOWS, CLOWNS, PRIZES GALORE [...] FOOD, ENTERTAINMENT, AND FUN FOR THE ENITRE FAMILY! SPECIAL NURSERY CENTER FOR YOUR CHILDREN" (Schwartz 2003, 135). 
More importantly however, by the 1970s, famous hotel chain Ramada Inns, Incorporated had entered the scene and purchased the Tropicana, declaring that this would mark a "new era for corporate growth" and that they were eager "to join the fast-growing casino gaming industry" and get a piece of what "appears to be [a] recession-resistant if not recession-proof" industry (Schwartz 2003, 163). The entry of a large hotel chain for the middle classes on the Strip took the management of Las Vegas' casino industry out of the hands of organized crime and transferred it to large, faceless corporations. Hence, Ramada Inns' faith in the power of gambling as a "recession-proof" economic driver and generator of wealth was accompanied by increased efforts to sanitize and expand Las Vegas and its gambling industries, which impacted radically on the geography of the city through the intense development of the Strip and its many themed casinos that mimic desert oases, medieval jousting rings, and pirate ships.

Beginning late in the 1980s, moreover, developer Steve Wynn began to dramatically reshape the economic landscape of Las Vegas again, this time by aggressively selling the city and its diversified leisure industries (theme parks, music venues, convention centers, shopping malls) on the market, and garnering the kind of capital investment needed to build mega resorts with thousands of rooms. This involved moving the industry overwhelmingly into the kind of elaborate mega theming whereby casinos are modelled as replicas of famous places such as Bellagio, New York, Paris, and Venice. These mega complexes, featured in films like Ocean's Eleven (USA: Steven Soderbergh, 2001), make Las Vegas a resort full of mini-destinations, as well as a convention and family entertainment center with multiple facilities such as shopping, swimming pools, various forms of gambling, as well as meeting rooms (Goggin 2010).

The corporatization of gambling - that is, the transfer of casino ownership from private developers like mafia boss Bugsy Siegel, who created The Flamingo on the Strip in 1946, to corporations made up of faceless investors and stockholders - as well as the view of gambling as a recession-proof industry are linked to what Susan Strange (1986) famously called "casino capitalism." This is to say that, where previously gambling was either illegal or sequestered, since the 1970s the casino industries are public offerings on the market. Or, put differently, whereas gambling was once prophylactically sealed and segregated from ostensibly legitimate economic practices, on river boats and in heterotopic centers like Reno and Vegas, it is now seen as an important economic driver around the globe. At the same time, the global market is driven by speculation, an activity that closely resembles gambling and is likewise based on risk taking. The two-gambling and 
speculation; the market and the gambling industries in which one may buy shares on the market - have become so fully merged that they are difficult to tell apart. Indeed, progressive deregulation of the financial markets in the twentieth century has made way for increasingly risky speculation, while neoliberalism has emerged as both a market force and "a cultural phenomenon expressing itself in casinopolitan culture as well as a particular political-economic constellation at work" on the global scene (Luke 2010, 397).

Hence, if Steve Wynn remarked in the 199os that "Las Vegas exists because it is a perfect reflection of America [...], journalists and academics alike have debated whether the rest of the country is becoming more like Las Vegas [...] [given] its status as the capital of the post-industrial economy" (Dow Schüll 2012, 7). What is more, where the gambling industries dominate, the tendency is to level anything on the extant landscape in typically neoliberal fashion, and remake it by erecting simulacra of Vegas-style simulacra of famous cities such as the Venetian, which has now spawned a fake twin Venice in Macau. In the following section, therefore, I want to extend this line of reasoning and turn my attention to some of the consequences entailed in the export of 007 and Las Vegas-style gaming to Macau.

\section{Skyfall and Macau}

Choosing a CGI simulation of Macau as the setting for the Bond franchise's trademark casino scene in Skyfall, rather than "Little Macau" as Las Vegas is sometimes called, parallels the current industrial migration of gambling from an American center, with its most important themed environments mimicking world cities, to a new, global arena. But the significance of setting Skyfall's casino scene in a simulated Macau becomes all the more evident when one considers the fact that most of the action in the movie takes places in the United Kingdom, resulting in a Bond film remarkably lacking in exotic tourist destinations. In this regard, the CGI oriental gambling palace in Skyfall is called upon to do double-duty by standing out as the film's most memorable and exotic location on the one hand, and supporting the franchise's need to project newness on the other while, as part of one of the revisionist prequels, signaling tradition by calling up the past in the form of references to Empire and the nostalgic Orientalism of Macau.

As Jen Hui Bon Hoa $(2012,1)$ argues, Skyfall's depiction of an "aging hero [...] no longer equal to the physical rigors of his job" parallels the film's 
portrayal of "an empire after the last colony has been surrendered" through its representation of the casino among an array of other signifiers of the past, such as M's China Bulldog. Hence, whereas previously Bond often operated and asserted his British superiority in (former) colonies, by the time Skyfall was made, Hong Kong (where the film's villain Silva [Javier Bardem] is stationed prior to the action of the movie) had been returned to the People's Republic of China. As a consequence, writes Hoa (2012, 6), the film treats Hong Kong with "coy indirection," featuring "no Hong Kong natives or locations nor any mention of Hong Kong's special status as the last bastion of the British Empire." Rather, Bond's pursuit of Silva in Skyfall takes him around the "geographical fringes of Hong Kong, to three different cities [sic.] in East Asia: Shanghai, Macau, and an unnamed island," with each of these places appearing "almost as encryptions of Hong Kong" through hints and inside jokes (6). In other words, Hong Kong is implicitly present yet largely absent from $S k y f a l l$ in comparison to Macau and Shanghai. According to Hoa, then, Skyfall's portrayal of Hong Kong by innuendo suggests that Britain's former colonial glory, as well as the kinds of portrayals of the colonies and colonial life that typify both Fleming's novels and the earlier film adaptations, is communicated in Skyfall by means of subtle suggestion and revisionism.

Like Hong Kong, Macau, a former Portuguese colony, was returned to the People's Republic of China in 1997. Yet, as Hoa $(2012,7)$ points out, once in Skyfall's "Macau," Bond finds himself in an environment saturated with signifiers of the island's colonial period, "beginning with the series of dragon-shaped arches through which he approaches the casino, [...] pet komodo dragons in a pit by the entrance, dragon sculptures inside the building, standard-issue cheongsams embroidered with dragons for the staff and, of course, a sinuous, chain-smoking femme fatale." In other words, the Macau casino in Skyfall has been retro-fitted to nostalgically recall old-time colonial casinos with the kinds of trappings that Hoa describes, now reproduced as mega-simulacra of a bye-gone era, ostensibly by the same Las-Vegas-based franchises that have established themselves in Macau and which are currently colonizing the much of the rest of the globe. The scenes that represent Macau also serve as an excellent example of how "Bond has successfully managed to acclimate to the changing social and political issues of the time [in which the film in question was being made, such as the Cold War in the earlier films and novels, or the shift from largely industrial capitalism to postindustrial capitalism] while being presented as the unattainable pinnacle of cool" (Wagner 2015, 51). This same strategy also "allows for Bond's oppressive colonizing and patriarchal behaviors to 
remain unchecked" (51) through, in this case, revisionism which involves the retro-feel and referencing of the casino.

The kinds of casinos that one would have encountered in Macau before the arrival of Vegas franchises following the colony's return to the People's Republic of China in 1997, such as the Casino Macau Palace, which housed only six baccarat tables, two blackjack tables, and two tables for sic-bo and dai-siu, were small scale affairs, the likes of which were featured in the 1974 film adaptation of The Man with the Golden Gun. In that earlier Bond film, the casino is filled with signifiers of the colonial period, such as the kind of dragon-festooned arches also featured in the CGI retro-themed Floating Dragon casino from Skyfall, while the street scenes in The Man with the Golden Gun are replete with rickshaws and impoverished children who attempt to sell 007 cheap souvenirs. The establishments we see in The Man with the Golden Gun, hosting largely local crowds, belonged to a "small traditional stretch of casinos" along the cargo wharves that held onto a "pretense of upper-crust European nightlife with white dinner jacket and formal dress" (Luke 2010, 397). These old casinos were run by "Macau monopoly holder Stanley Ho [who] turned over management of VIP gaming rooms in his casinos to Chinese triad operators who began violent campaigns to protect their turf, creating an increasingly lawless atmosphere" (Simpson 2012, 15). However, with the transfer of sovereignty from Portugal to the People's Republic in 1997, the Macau government decided to refashion its urban space around allegedly "larger, more wholesome Las Vegas-style operations" (Kurlantzick 2005, 286; Luke 2010, 399), as reflected in the digitally designed Floating Dragon created in the Pinewood Studios and featured in Skyfall.

The "real" Macau now boasts a number of mega complexes that replicate Las Vegas casinos such as The Rio, Wynn Vegas, The Riviera, The Sands, MGM, and The Flamingo, the importation of which signals deep structural, economic and cultural changes, such as the shift from being a colony of one country to another; entering the global economy; the restructuring of the island's economy to one predominantly based on gambling; a much-changed landscape full of neon-themed casino complexes; a major restructuring of the job market; and the necessity of a late-night work force.

Ironically, the processes of legitimizing and sanitizing the gambling industries, initiated by casino operators and state legislators in Las Vegas with the 1967 Gambling Act, has resulted in Vegas casinos being regarded as a quasi-policing mechanism. Hence, as Tim Simpson has written, by the twenty-first century, the Las Vegas gaming industries had become so legitimized that the Macau government awarded gaming concessions to 
Steve Wynn and Sheldon Adelson-Las Vegas kingpins, casino developers and operators - hoping that their investment would develop the economy and restore law and order. "Knowing that casino operators in Vegas were bound to follow the regulations of the Nevada Gaming Commission or risk losing their license in Nevada, Macau bet on the fact that the rule of law in the United States would work indirectly to police Macau" (Simpson 2012, 15). This applies to issues such as surveillance, security, and financing, and includes the Las Vegas rule that casinos must hold enough cash in reserve to cover every marker on the floor at any given time.

American casino industries inject soft forms of governance around issues concerning employment, business practices and surveillance into the local economy of countries where they set up shop, acting as regulatory industries and policing measures. This is no small feat if one takes into account Steve Wynn's ("Steve Wynn" 2016) own confession in a CNN interview that the kind of large-scale, industrial colonialization that he has undertaken in Macau has "political ramifications and political consequences" as "the leadership of Macau wrestles with all of the competitive forces at work." When coupled with Wynn's obsession with security and his work on radio frequency identity (RFID) chips, which help to identify counterfeit chips, rate players for bonuses that will keep them at the slots, and deter casino cheats, the implications are staggering if not yet fully realized.

Quite obviously, at least one peculiar irony arises here from the consideration that importing Las Vegas franchises amounts to importing US law. Like Bond, a secret agent who famously polices the globe, American gambling franchises have been brought into various global destinations with the surreptitious purpose of policing the local population and economy as outlined above. Unlike the older Macau casinos which I described previously, the casino in Skyfall retains something of a "glocal" oriental flavor yet it is still decidedly Americanized, which suggests that, just as various signifiers of Bond are known and mobilized around the globe, so too is the Western practice of industrializing gambling that dramatically transforms the cultures into which it is imported. At the same time, what was previously Macau has now been raised and refitted with casinos

1 One such consequence is the restructuring of the island's economy to operate through Las Vegas franchises which are famous for negative externalities such as gambling addiction, public drunkenness and rowdy behavior and violence, as well as indolence caused by this negative cluster of outcomes in the local population. As yet, there is little or no work available on the Americanization of Macau's local cultures and Wynn is notably vague in the interview about whatever "political ramifications and political consequences" there are now or may be in the future. See "Steve Wynn: A true showman." 2016. CNN Talk Asia. 
with names like "The Sands" that recall old-fashioned establishments from the "Rat-Pack" hay days of Las Vegas, thus rehearsing the logic of neoliberalism that erases the past in order to reinstate some odd, newlyminted form of tradition. But given that, in this case, the tradition being referenced comes from Las Vegas, the kind of casinopolism taking hold in Macau is more aptly described as "Vegas-ization," since it amounts to the full-scale importation of the feel and landscape of one city (Las Vegas), itself comprised of simulacra of other cities (Paris, New York, Bellagio, Venice). This shift has significant consequences, which, I suggest, will include the shrinkage of what were previously Macau's pillar industries (manufacturing, construction and real estate, financial services), increased gambling addiction, an economy almost entirely based on service industries, increased prostitution, tourist debauchery, and, ironically, increased lawlessness (Mingjie Sheng and Chaolin Gu 2018).

Furthermore, the neoliberal logic of levelling whatever is perceived as standing in the way of economic "progress" in order to (re)establish a largely fictional, nostalgic, and revisionist version of the past, while impacting on everything from the political system to the indigenous culture and economy, is bizarrely redoubled in Skyfall. The film's Macau casino, which suggests a sort of vintage Vegas-style oriental gambling resort, is non-existent and was created to reflect the kind of image that viewers might conjure up if asked to imagine an oriental casino in an exotic location. True to the Las Vegas tradition, the mock-up casino is themed to represent an urban location out of the past, much like the Paris, Venice or New York, New York casino complexes in Vegas, but the "order of simulacrum" (to borrow Jean Baudrillard's [1983] term) is enhanced by the fact that this is a non-existent casino. This gesture is all the more radical considering that none of the scenes in Skyfall were actually shot on location in Macau: rather, Macau itself was entirely created with CGI for the film, with one blogger (Sterling 2013) suggesting that "most likely [the producers] felt that Macau would be more exotic portrayed like something from the colonial era." In other words, neoliberalized societies and the economies in which they operate are, it would appear, more comfortable with sentimental - if gritty - revisionist simulations of an imagined past world that never existed than they are with the "real" world of the Global South. The casino scene in Skyfall, and the kinds of signifiers and the politics of contemporary, global casino culture that it depicts, is an excellent example of how the neoliberalized global economy is expressed in revisionist cinema. 


\section{Conclusion}

Umberto Eco $(2009,45)$ wrote of his "suspicion that [Fleming] does not characterize his creations in such and such a manner as a result of ideological opinion but purely for rhetorical purposes" by exploiting endoxa or "the common opinions shared by the majority of readers," which ultimately made him "an expert in tale engineering." Whether or not, as Eco suggests, Fleming himself was as cynical about the inherent ideology of what he was up to, the result is a fictional universe with the capacity to make a serious, real-world impact. In keeping with these observations, I have argued that $S k y f a l l$, as a post-Fleming revisionist outing of a franchise calculated to communicate "nowness," expresses, directly or indirectly, a neoliberal ideology and gives voice to particular economic practices such as deregulation, corporatization, casinofication, Lasvegasization, and financialization. The film does all of this by negotiating its relationship with the past and the future from its situation in the present through the many signifiers of Bond, in particular by way of its representation of gambling and casinos. In so doing, the film - and indeed the Daniel Craig quadrilogy more generally — shares a number of features with wider trends not only in blockbuster cinema but also with specific aspects of neoliberal (geo)politics and economics: first and foremost, the practice of erasing or eradicating the past in order to (re)create a present that references an imaginary past, which itself answers to the demands of current neoliberal ideologies. In other words, when Silva asks Bond if he has a hobby, his answer- "resurrection"-is more than just an amusing quip. As we know, Bond has a nasty habit of surviving, but it is the how of his continuance that keeps us watching and waiting for the next instalment. In the current moment of Bond, it would seem that to innovate means going "back in time, where we have the home field advantage," as oo7's dredged up father figure, Kincade (Albert Finney), explains in Skyfall.

\section{Works Cited}

Baudrillard, Jean. 1983. Simulations, translated by Paul Foss, Paul Paton and Philip Beitchman. New York: Semiotext(e).

Bennett, Tony, and Janet Woollacott. 1987. Bond and Beyond: The Political Career of a Popular Hero. New York: Routledge.

Bjerg, Ole. 2011. Poker: The Parody of Capitalism. Ann Arbor: The University of Michigan Press. 
Chapman, James. 1999. Licence to Thrill: A Cultural History of the James Bond Films. London: I.B. Tauris.

Chapman, James. 2005. "Bond and Britishness." In Ian Fleming and James Bond: The Cultural Politics of oo7, edited by Edward P. Comentale, Stephen Watt, and Skip Willman, 55-63. Bloomington: Indiana University Press.

Denning, Michael. 2009. The James Bond Phenomenon: A Critical Reader, Second Edition, edited by Christoph Lindner, 56-75. Manchester: Manchester University Press.

Dodds, Klaus. 2014. "Shaking and Stirring James Bond: Age, Gender, and Resilience in Skyfall (2012)." Journal of Popular Film and Television 42, no. 3: 116-30.

Dow Schüll, Natasha. 2012. Addiction by Design: Machine Gambling in Las Vegas. Princeton: Princeton University Press.

Eco, Umberto. 2009. The James Bond Phenomenon: A Critical Reader, Second Edition, edited by Christoph Lindner, 34-55. Manchester: Manchester University Press.

Fleming, Ian. 1953. Casino Royale. London: Jonathan Cape.

Fleming, Ian. 1956. Diamonds are Forever. London: Jonathan Cape.

Gehlawat, Monika. 2010. Revisioning oo7:James Bond and Casino Royale, edited by Christoph Lindner, 131-44. New York: Wallflower.

Goggin, Joyce. 2010. "From Remake to Sequel: Ocean's Eleven and Ocean's Twelve." In Second Takes: Approaches to the Film Sequel, edited by Caroline Jess-Cooke and Constantine Verevis, 105-21. Albany: State University of New York Press.

Goggin, Joyce, and René Glas. 2010. "It Just Keeps Getting Bigger: Bond and the Political Economy of Huge." In Revisioning oo7:James Bond and Casino Royale, edited by Christoph Lindner, 50-70. New York: Wallflower Press.

Goggin, Joyce. 2011. "oo7 Does Vegas: The Diamond Standard and the Experience Economy." The Cultures ofJames Bond, edited by Joachim Frenk and Christian Krug, 65-81. Trier: Wissenschaflicher Verlag Trier.

Goggin, Joyce. 2015. "Opening Shots and Loose Slots.” Screen 56, no. 2, Special Issue on "Opening Pages, Opening Shots," edited by Christine Geraghty and Shannon Wells-Lassagne: $245^{-5}$.

Harman, Chris. 2009. Zombie Capitalism: Global Crisis and the Relevance of Marx. Chicago: Haymarket Books.

Hasian Jr., Marouf. 2014. “Skyfall, James Bond's Resurrection, and 21st-Century Anglo-American Imperial Nostalgia." Communication Quarterly 62, no. 5:569-88.

Higson, Charlie. 2012. "James Bond: Nobody Does It Better." The Daily Telegraph, October 19.

Hoa, Jen Hui Bon. 2012."'That Which We Are, We Are': Hong Kong and Post-Colonial Identity in Skyfall." Situations 6 (Winter): 1-11.

Klein, Naomi. 2007. The Shock Doctrine: The Rise of Disaster Capitalism. London: Penguin. 
Kurlantzick, Joshua. 2005. “The Decline of American Soft Power." Current History 104, no. 686 (December): 419-24.

Lindner, Christoph. 20og. "Introduction." In The James Bond Phenomenon: A Critical Reader, Second Edition, 1-13. Manchester: Manchester University Press.

LiPuma, Ed. 2017. The Social Life of Financial Derivatives: Markets, Risk and Time. Durham: Duke University Press.

Luke. Timothy W. 2010. "Gaming Space: Casinopolitan Globalism from Las Vegas to Macau”. Globalizations 7, no. 3: 395-405.

Owens, Craig N. 2005. "The Bond Market." In Ian Fleming and James Bond: The Cultural Politics of oo7, edited by Edward P. Comentale,, Stephen Watt, and Skip Willman,107-29. Bloomington: Indiana University Press.

Packer, Jeremy. 2009. Secret Agents: Popular Icons Beyond James Bond. New York: Peter Lang.

Parlett, David. 1992. A Dictionary of Card Games. Oxford: Oxford University Press.

Rothman, Hal. 2003. Neon Metropolis: How Las Vegas Started the Twenty-First Century. London: Routledge.

Taylor, Mark. 2004. Confidence Games: Money and Markets in a World without Redemption. Chicago: The University of Chicago Press.

Schwartz, David G. 2003. Suburban Xanadu: The Casino Resort on the Las Vegas Strip and Beyond. New York: Routledge.

Sheng, Mingjie, and Chaolin Gu. 2018. "Economic Growth and Development in Macau (1999-2016): The Role of the Booming Gaming Industry." Cities 75 (May 2018): 72-80.

Simpson, Tim. 2012. “Tourist Utopias: Las Vegas, Dubai, Macau." Asia Research Institute Working Paper Series 177, National University of Singapore: 1-27.

Sterling, R. 2013. "Portuguese Macau." James Bond Locations, Last Accessed on August 1, 2019, https://jamesbondlocations.blogspot.nl/2013/05/portuguesemacau.html).

“Steve Wynn: A true showman.” 2016. CNNAsia, Accessed January 14, 2019, http:// edition.cnn.com/videos/world/2016/10/o6/talk-asia-steve-wynn-spc-a.cnn.

Strange, Susan. 1986. Casino Capitalism. Oxford: Blackwell.

Vegasmaster. 2016. “The Best Scenes in Casinos in James Bond Movies”. Last Accessed October 21, 2016, http://www.vegasmaster.com/the-best-scenes-in-casinos-injames-bond-movies/.

Wagner, Travis. 2015. "The Old Ways are Best: The Colonization of Women of Color in Bond Films." In For His Eyes Only: The Women ofJames Bond, edited by Lisa Funnell, 51-59. New York: Wallflower.

Winder, Simon. 2006. The Man Who Saved Britain: A Personal Journey into the Disturbing World ofJames Bond. New York: Picador. 


\section{About the Author}

Joyce Goggin is a Senior Lecturer in Literature at the University of Amsterdam. She has published widely on gambling and finance in literature, painting, film, television, and computer games. Her recent publications include a co-edited collection of essays entitled The Aesthetics and Affects of Cuteness (Routledge 2017), and she is currently completing a translation of two eighteenth-century Dutch comedies by Pieter Langendijk on the South Sea Bubble, forthcoming with Liverpool University Press in 2020. A book chapter on the novelizations of The LEGO Movie has also been published in Cultural Studies of LEGO: More Than Just Bricks (Palgrave 2019). 
